\title{
Research and Applications of Course System Framework Based on Unit Wei Liu ${ }^{1}$, Qiangwei Yan² \\ ${ }^{1}$ Department of Information Engineering, Wuhan Business University, Wuhan, 430056, China ${ }^{2}$ Wuhan Textile University, Wuhan, 430200, China \\ * Corresponding author: Qiangwei Yan
}

Keywords: unit, course system, interdisciplinary, mobile game

\begin{abstract}
In this paper, we propose a framework of curriculum system based on configurable units, which is suitable for the undergraduate education and higher vocational education.The framework of the course can transform the existing curriculum system into a modular curriculum system, and ensure the flexible configuration and quality control of the modules. The framework of the course system is applied to design the mobile games in the paper.
\end{abstract}

\section{Introduction}

Higher education not only requires students to master solid professional basis, but also requires the students to have more fusion and application ability in the face of complicated work problems. The current college professional settings, has become more prominent, more professional and more knowledge fusion ability; at the same time, in order to cope with the domestic economic restructuring and the rapid economic development of the Internet rapidly changing demand for talent, colleges and universities in the new method to try talents education, while its foothold in the reform of the curriculum on. Whether it is for the task, for the position, ability or other professional setting concept cannot get rid of cross curricular, interdisciplinary curriculum. Due to the cross knowledge, cross curricular and interdisciplinary curriculum has many different applications, for example in the university curriculum, will build one or more characteristics of the professional line in which the professional line of the professional courses are usually combined knowledge, some may involve more than one similar to professional knowledge, so the knowledge of how to integrate and coordinate; and as a future work required ability, need two or more different professional knowledge to support, or a task requires multiple different professional personnel to complete the cooperation, how to develop own interdisciplinary cohesion and comprehensive ability of talent, requires a different department to execute. For example, some colleges and universities have both undergraduate education and vocational education. It may be set at the same time on these two levels. In view of the different levels of education, we can design a flexible configuration of the curriculum system, and apply to the college and vocational education, to achieve the optimization of educational resources. In order to deal with these problems, it is necessary for colleges and universities to carry out the new design on the structural level of curriculum. 


\section{Interdisciplinary course framework with configurable units}

This paper puts forward a curriculum arrangement framework based on configurable units, which is suitable for undergraduate education and higher vocational education.

Before defining the unit, two concepts are defined as follows. Curriculum: a course for students' daily learning, which is the smallest unit in the framework of configurable unit curriculum. The main teaching: is a professional line of professional training goal, it can be used to complete a multi knowledge fusion teaching objectives, or training students to complete a job and a kind of compound has the ability.

Unit: in the course of teaching, in order to achieve certain teaching goals, or to integrate a system of knowledge, will be two or more than two courses, grouping and integration according to the target, one after the integration of the packet is called a unit.

Integration of curriculum units: the curriculum within the unit is a combination of a certain target, there is a correlation between the content of each course and order. The courses in the unit are linked, which will be taken into account when the unit is designed. The cohesive relation can be the cohesion of the course content, or can be connected by some practice.

Unit assessment: each course and practice content within the unit can be individually assessed. After the completion of unit teaching, we must carry out comprehensive assessment of the unit.

Unit duration: the duration of a unit is not limited to one semester, it can be two, or even more than a semester, the course has a good convergence within the unit, the time does not affect the convergence.

In the unit of each course has a teacher teaching, because each course teaching content and teaching objectives in professional settings are set to ensure that the objectives of this although curriculum in the professional teaching, but when this course as a part of some other teaching points, or as a cross discipline other professional courses, the goal of the teaching content, may be inconsistent with the expected teaching goal, which leads to cross courses such lack of practical significance. This problem can be solved by forming a teaching unit. We consider the integrated curriculum unit as a module. Units cannot be set too much, too many units will make the nature of convergence with the general curriculum, the loss of the actual meaning of the unit. So how to ensure the flexibility of the teaching unit, and make it in the main line of teaching can always meet the requirements of the teaching objectives, we introduced the unit responsible person mechanism. After the completion of unit teaching, we must carry out mechanism of the unit head.

The unit is responsible for each teaching unit manager, he according to the entire unit teaching goals, solely responsible for the whole unit set, including the teaching content of each course, each course connection between the comprehensive practical content of the whole unit, unit evaluation and audit unit course materials. The unit responsible for the mechanism, the unit has become a flexible teaching module, the degree of flexibility it can be like a single course, are inserted into any professional or teaching tasks. According to the requirements of the main line, the unit responsible for the dynamic adjustment of all the courses within the unit, and planning the content of the course, but also in accordance with the different characteristics of teachers, adjust the teaching unit within the course. 
The person in charge of the unit design unit, first need to communicate and plan with their upper level, clear the main teaching and teaching objectives; also need to communicate with the students understand the basic knowledge, the students' interest and willingness, learning in occupation planning; in addition, the unit responsible person may also need experts and business communication, fully understand the main technical development and the demand for talents in the industry. In order to fully understand the teaching objectives, needs and resources, the unit responsible for the dynamic planning of the contents of each course in the unit, combined with the scope of the existing teachers. Aiming at the unit target, content settings can be refined to a knowledge point, which can shield away from the target knowledge, such benefits is to reduce spending on unnecessary knowledge on the time, focus on teaching centre, improve teaching efficiency, and strengthen the connection between each course.

In recognition of the unit can be configured after the unit is an independent application module, different teaching, different majors can be placed in teaching a module, or even the whole course can be built into a plurality of modules. If the professional development allows students to choose the direction of professional development, you can set different directions in different units for students to choose.

Some universities will also have a college education and undergraduate education, and similar professional settings in two different levels of education, such as college level computer application technology professional and undergraduate software engineering, both of which are in favour of professional software development. Although the professional degree is very high, but the undergraduate course and the specialized subject has the obvious difference in the teaching content, the use of configurable unit curriculum framework can be very good in two different levels of education to achieve teaching resources sharing. As a unit, not only can be used in undergraduate education and can be used in college education, unit responsible person can dynamically adjust the unit in the course content, curriculum content, curriculum practice, practice curriculum assessment content and assessment unit.

\section{Course system design of mobile game based on unit}

In this paper, we have designed a set of highly efficient mobile game design curriculum system for the majority of colleges and universities, which is based on the framework of configurable unit curriculum. The curriculum system will be the entire game design, development, promotion and operation and maintenance of the latter is divided into three large units, the relevant professional can be set up in any one of them as the main line. We set up a number of small units in each large cell. Each small unit can be used as a professional course module or a cross disciplinary teaching module to be implanted, or as a knowledge integration, set to a single direction in a professional teaching.

Game design and development unit is mainly concentrated in the computer technology, including the game logic design, content design, the operation of the game engine, based on the game engine to achieve the program, the formation and release of the game APP. The unit can be configured in the undergraduate and vocational education related professional. After the completion of the unit, 
the students should have the ability to include: familiar with all types of existing mobile games, according to the existing game type, logic and mode of operation, the contents of the design of similar games. Master the operation of a mainstream mobile game engine, and master the technical requirements of the engine programming. Master the method of game platform and peripheral software cooperation. Master the interaction between the game engine and the mobile operating system, to generate APP for multi operating system, and to complete the test and follow-up APP upgrade.

Visual design unit. The visual design unit is mainly responsible for the mobile game and all display and effects related work, including two-dimensional design, UI design, 2D and 3D character design, scene design, props design, specific design. According to the difference among the 2D and 3D or 2.5 dimensions of game screen style, we choose the small unit which can configure the education unit or undergraduate and higher vocational colleges. The ability to complete the unit can master the skills are as follows: 2D and UI design ability. The digital expression and implementation of three-dimensional design and modeling capabilitiesinclude the three-dimensional scenes, characters and props.

It is responsible for the promotion of mobile games and post operational issues, including game promotion, income generating strategies, operations management. But it does not include the technical aspects of operations. The completion of the unit after learning, including the students' ability to master: the game was released early and running multi-channel promotion strategy; multichannel revenue strategy game based on product platform; operation and management, customer service and customer service management.

\section{Conclusion}

The curriculum framework based on unit has its inherent advantages. It is very flexible to build a knowledge system and realize the modular teaching. Of course, the shortcoming of the curriculum system is obvious. It requires good quality of the professional performance, forward-looking ability and communication skills of the unit head, which may lead to the hidden problems of the unit.

\section{References}

[1] Hamilton J G, Experiential Learning: A Course Design Process for Critical Thinking, American Journal of Business Education, 2016, 4(12): 1.

[2] Hussey H D, Fleck B K B, Richmond A S, Promoting active learning through a flipped course design, Promoting Active Learning Through the Flipped Classroom Model, 2014: 23-46.

[3] Kali Y, Mckenney S, Sagy O, Teachers as designers of technology enhanced learning, Instructional Science, 2015, 43(2):173-179.

[4] Dickson P E, Experiences building a college video game design course, Journal of Computing Sciences in Colleges, 2010, 25(6):104-110.

[5] Ranalli J, Ritzko J, Assessing the impact of video game based design projects in a first year engineering design course, 2013:530-534. 